[Article]

\title{
单壁碳纳米管上毒性苯气体净化的分子模拟
}

\author{
彭 璇* \\ (北京化工大学信息科学与技术学院, 北京 100029)
}

\begin{abstract}
摘要: 采用巨正则系综蒙特卡罗(GCMC)方法研究了空气中微量苯组分在单臂碳纳米管(SWNTs)上的吸附净 化. 模拟表明, 具有较大孔径的 $(20,20)$ 纳米管比较适合吸附纯苯蒸汽, 而对于移除空气中的毒性苯物质, 苯的 吸附选择性分别在(12,12)纳米管及 $4.0 \mathrm{MPa}$ 时和 $(18,18)$ 纳米管及 $0.1 \mathrm{MPa}$ 时出现最小值和最大值. 为了解释 这一异常行为, 我们进一步分析了 $\mathrm{N}_{2}-\mathrm{O}_{2}-\mathrm{C}_{6} \mathrm{H}_{6}$ 混合物的局部密度分布、吸附分子构型和概率密度分布, 发现(18, 18)纳米管内外完全被苯分子占据, 而对于 $(12,12)$ 纳米管, 由于存在更强的吸附质-吸附剂相互作用, 空气分子 更倾向于吸附在管与管之间的间隙. 此外, 吸附分子的空间有序参数表明大多数苯分子采取 “平躺” 在纳米管表 面的定位, 而线性的 $\mathrm{N}_{2}$ 和 $\mathrm{O}_{2}$ 分子则多数平行于孔轴方向. 最后研究了温度和苯分子主体相浓度对分离效果的 影响. 我们发现较大孔中的选择性随着温度的增加比小孔下降更加明显. 与此对比, 主体相苯浓度对小孔中的 选择性起到更加重要的作用.
\end{abstract}

关键词: 巨正则系综蒙特卡罗; 吸附; 分离; 苯; 空气；碳纳米管

中图分类号: 0647

\section{Molecular Simulations of the Purification of Toxic Benzene Gas on Single-Walled Carbon Nanotubes}

\author{
PENG Xuan* \\ (College of Information Science and Technology, Beijing University of Chemical Technology, Beijing 100029, P. R. China)
}

\begin{abstract}
Grand canonical ensemble Monte Carlo (GCMC) simulations were performed to investigate the purification of benzene from air by single-walled carbon nanotubes (SWNTs). It was found that $(20,20)$ SWNT with a large diameter is suitable to adsorb pure benzene. For the removal of benzene in air, the minimum and maximum selectivities were observed for the $(12,12)$ SWNT at $4.0 \mathrm{MPa}$ and the $(18,18)$ SWNT at $0.1 \mathrm{MPa}$, respectively. To obtain deep insight into the unusual behavior, we analyzed the local density profiles, snapshots, and probability profiles of $\mathrm{N}_{2}-\mathrm{O}_{2}-\mathrm{C}_{6} \mathrm{H}_{6}$ mixtures. The results showed that the $(18,18)$ SWNT was entirely occupied by benzene molecules, while, for the $(12,12)$ SWNT, $\mathrm{N}_{2}$ and $\mathrm{O}_{2}$ were prone to appear in the interstices between tubes, instead of inside tubes, because of stronger adsorbate-adsorbent interactions. Additionally, we calculated the orientation order parameters of the adsorbates. The results suggested that benzene molecules prefer lying nearly flat on the pore surface, while $\mathrm{N}_{2}$ and $\mathrm{O}_{2}$ molecules orient parallel to the pore axis. Finally, the effects of temperature and concentration on the selectivity of benzene were investigated. We found that with increasing temperature the selectivity in large pores decreased more evidently than that in small pores. By contrast, the concentration plays a more important role in affecting the selectivity in small pores.
\end{abstract}

Key Words: Grand canonical ensemble Monte Carlo; Adsorption; Separation; Benzene; Air; Carbon nanotube

Received: June 4, 2014; Revised: August 29, 2014; Published on Web: August 29, 2014.

"Corresponding author. Email: pengxuan@mail.buct.edu.cn, pengxuan@126.com; Tel: +86-10-64430917.

The project was supported by the Open Project of State Key Laboratory of Chemical Engineering, China (SKL-Che-12C01).

化学工程联合国家重点实验室开放课题(SKL-Che-12C01)资助

(C) Editorial office of Acta Physico-Chimica Sinica 


\section{Introduction}

In the production process of spraying, printing, leather processing that use large amounts of organic solvents, there will escape waste gas containing the substances of benzene, toluene, and xylene. It is reported that a concentration in the air as low as $100 \times 10^{-6}$ is considered to constitute a definite hazard. ${ }^{1}$ Directly releasing the waste gas to atmosphere is closely related to environmental pollution and health safety. Consequently, control of their emissions has become increasingly urgent and crucial importance on global atmospheric chemistry and quality of life. The treatment of the waste gas includes catalytic combustion method, absorption method, biochemical method, and adsorption method. ${ }^{2}$ At present, a more consistent view is to use the adsorption method.

Up to now, adsorptions of benzene on the adsorbent materials such as activated carbons, zeolites, and metal organic frameworks $(\mathrm{MOFs})^{3,4}$ have been widely studied. Do and $\mathrm{Do}^{5}$ investigated the effect of intermolecular potential models on the adsorption of benzene on graphitized thermal carbon black. Coasne et al. ${ }^{6}$ investigated the structure and dynamics of benzene confined in the MCM-41 silica nanopores with different diameters by means of grand canonical Monte Carlo (GCMC) and molecular dynamics simulations. Similarly, Jousse et al. ${ }^{7}$ performed a variety of force field based simulations to study the location and diffusion of benzene adsorbed in a model zeolite $\mathrm{HY}$ with the $\mathrm{Si} / \mathrm{Al}$ mole ratio of 2.43. Amirjalayer et al. ${ }^{8}$ performed molecular dynamic simulations to investigate the effect of lattice dynamics on the benzene diffusion in MOFs. Besides the adsorbents mentioned, carbon nanotube is also an extremely important porous material. Since Iijima $^{9}$ discovered the carbon nanotubes in 1991, there appear numerous experimental and computational studies on the application of carbon nanotubes, especially for single-walled carbon nanotubes (SWNTs). ${ }^{10-12}$ For example, Cinke et al. ${ }^{10}$ discovered that the SWNTs can adsorb nearly twice the volume of $\mathrm{CO}_{2}$, compared to activated carbon. Wang et al. ${ }^{11}$ investigated the selective adsorption of $\mathrm{H}_{2} \mathrm{~S}$ and $\mathrm{SO}_{2}$ from natural gas and flue gas via GCMC method and found that the SWNTs with optimized pore sizes were particularly suitable to capture trace sulfur gases. Huang et al. ${ }^{12}$ simulated the adsorption separation of equimolar $\mathrm{CH}_{4}-\mathrm{CO}_{2}$ mixture and found that the SWNTs have a higher selectivity of $\mathrm{CO}_{2}$ than activated carbon, zeolites $13 \mathrm{X}$, and MOFs.

It seems that SWNTs could be very promising to gas storage and separation for their unique pore structure, modifiable surface chemistry, and controlled pore sizes. However, to our knowledge, the data of the adsorption efficiency and optimum conditions for single and mixed benzene pollutants are still very rare, and these data are the extremely important parameters of design and operation for the pressure swing adsorption (PSA) process. In this paper, by performing molecular simulations for the ternary mixture of $\mathrm{C}_{6} \mathrm{H}_{6}, \mathrm{~N}_{2}$, and $\mathrm{O}_{2}$, we systematically investigate the effects of temperature, pressure, pore size, and benzene concentration on the adsorption behavior of SWNTs. It is expected that this work can provide theoretical basis for the carbon nanotube adsorption treatment of waste gas containing low concentration of benzene in engineering design and practice, as well as the control of reasonable process parameters.

\section{Molecular simulations}

In our simulations, air is regarded as a mixture of $\mathrm{N}_{2}$ and $\mathrm{O}_{2}$ with an approximate mole ratio of 79:21. All-atom forcefield is used to represent the three fluid molecules. Benzene is described by a nine-site potential, ${ }^{13}$ where the positive charge of $+8.130 e$ is located at the ring center, and two negative charges of $-4.065 \mathrm{e}$ represent the $\pi$-electron clouds above and below the benzene ring. The negative charges are located at a position $z= \pm 0.4 \mathrm{~nm}$ along the symmetry axis normal to the benzene ring. Each $\mathrm{CH}$ group is represented as a single interaction site that interacts with a Lennard-Jones (LJ) potential. For oxygen molecules, we used the two-site LJ intermolecular potential model from Perng et al., ${ }^{14}$ where the two sites are centered on the nuclear positions and their LJ parameters are determined by fitting experimental liquid phase diagram to the molecular dynamics simulations. Similarly, the potential model of $\mathrm{N}_{2}$ is taken from the three-site TraPPE force field optimized for VLE calculations. ${ }^{15}$ Each nitrogen atom is modeled by a LJ site separated by the experimental bond length of $0.11 \mathrm{~nm}$. A point charge of $-0.482 e$ is placed on each LJ site. To maintain charge neutrality, a point charge of $+0.964 e$ is placed at the center of mass $(\mathrm{COM})$ of the $\mathrm{N}_{2}$ molecule. The cross interaction parameters are obtained by the Lorentz-Berthelot combining rules. All the size and energy parameters of adsorbates and adsorbent are given in Table 1.

GCMC simulations ${ }^{16}$ are carried out to investigate the gas adsorptions inside SWNT and in the interstices between SWNTs. The SWNT bundles are frozen as a hexagonal structure with the tube-tube separation of $0.4 \mathrm{~nm},{ }^{17}$ as shown in Fig.1. This separation distance of $0.4 \mathrm{~nm}$ is determined by the experimental data and also used in the Kowalczyk's simulations. ${ }^{17}$ All the SWNTs are cut off at the $z$ direction with a length of $2.705 \mathrm{~nm}$. The numbers of unit cells for $(18,18)$ and $(20,20)$ SWNTs are $1 \times 1 \times 1$, while for others SWNT bundles they are $2 \times 1 \times 1$. The structural properties of SWNTs are given in Table 2 .

For all the materials, the periodic boundary conditions are applied in three dimensions ( $x, y$, and $z$ directions). The spherical cutoff of $1.2 \mathrm{~nm}$ is used to calculate the intermolecular LJ interactions without long-range corrections. The electrostatic interaction between fluids is handled by the Wolf spherically truncated method $^{18}$ and the cutoff is also set to $1.2 \mathrm{~nm}$. To accelerate the simulations, the LJ interactions between adsorbates and SWNTs are interpolated from a pretabulated energy map with the grid spacing of $0.02 \mathrm{~nm}$. A total number of $2 \times 10^{7}$ configurations are generated at every state. The first $10^{7}$ configurations are discarded to guarantee equilibration, whereas the remained ones are divided into 20 blocks for ensemble average. For all the species, the GCMC procedure will move randomly in translation, rotation, insertion, and deletion. Instead of using the chemical potential, the normal move acceptance probabilities are transformed in the forms of the component fugacity of bulk phase, which is calcu- 
Table 1 Lennard-Jones and coulombic potential parameters for $\mathrm{C}_{6} \mathrm{H}_{6}, \mathbf{N}_{2}, \mathrm{O}_{2}$, and SWNT

\begin{tabular}{clc}
\hline & \multicolumn{1}{c}{ Parameter } & Value \\
\hline $\mathrm{C}_{6} \mathrm{H}_{6}$ & $r(\mathrm{CH}-\mathrm{CH}) / \mathrm{nm}$ & 0.1715 \\
& $q(z=0.0 \mathrm{~nm}) / e$ & +8.130 \\
& $q(z= \pm 0.04 \mathrm{~nm}) / e$ & -4.065 \\
& $\sigma_{\mathrm{CH}} / \mathrm{nm}$ & 0.3361 \\
& $\left(\varepsilon_{\mathrm{CH}} / k_{\mathrm{B}}\right) / \mathrm{K}$ & 75.6 \\
$\mathrm{~N}_{2}$ & $r(\mathrm{~N}-\mathrm{N}) / \mathrm{nm}$ & 0.11 \\
& $q(z=0.0 \mathrm{~nm}) / e$ & +0.964 \\
& $q(z= \pm 0.055 \mathrm{~nm}) / e$ & -0.482 \\
& $\sigma_{\mathrm{N}} / \mathrm{nm}$ & 0.331 \\
& $\left(\varepsilon_{\mathrm{N}} / k_{\mathrm{B}}\right) / \mathrm{K}$ & 36.0 \\
& $r(\mathrm{O}-\mathrm{O}) / \mathrm{nm}$ & 0.1208 \\
$\mathrm{O}_{2}$ & $\sigma_{\mathrm{o}} / \mathrm{nm}$ & 0.3006 \\
& $\left(\varepsilon_{\mathrm{o}} / k_{\mathrm{B}}\right) / \mathrm{K}$ & 48.0 \\
& $\sigma_{\mathrm{c}} / \mathrm{nm}$ & 0.34 \\
$\mathrm{SWNT}$ & $\left(\varepsilon_{\mathrm{c}} / k_{\mathrm{B}}\right) / \mathrm{K}$ & 28.0 \\
& &
\end{tabular}

$r$ is the bond length of the molecules, $q$ is the partial charge of the interaction sites, $\sigma$ and $\varepsilon$ are the size and energy parameters of

Lennard-Jones potential, respectively.

lated by Peng-Robinson equation of state.

The isosteric heat $\left(q_{\mathrm{st}}\right)$ that reflects the affinity between adsorbent and adsorbates is approximated by ${ }^{19}$

$$
q_{\mathrm{st}} \approx R T-\left(\frac{\partial U}{\partial N}\right)_{T, V}
$$

where $R$ and $T$ are the universal gas constant and temperature, and $U$ and $N$ are the total adsorbed energy and number of fluid particles, respectively.

Adsorption selectivity of component $i$ over $j$ in a mixture is defined as ${ }^{20}$

$$
S_{i j j}=\left(\frac{x_{i}}{x_{j}}\right)\left(\frac{y_{j}}{y_{i}}\right)
$$

where $x, y$ are the mole fractions of component for the adsorbed and bulk phase, respectively.

The orientation order parameter ${ }^{6}$ of molecules with respect to the pore axis is given by a function of the distance $r$ from the simulation box center to the molecular mass center

$$
S_{z}(r)=\left\langle\frac{3}{2} \cos ^{2} \beta-\frac{1}{2}\right\rangle
$$

where the brackets in the equation above denote an average over

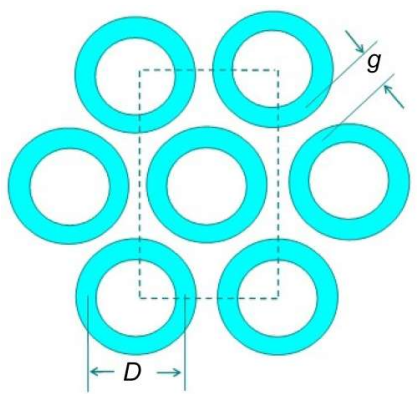

Fig.1 A hexagonally-arranged model of SWNT materials The area within dashed lines denotes a unit-cell used in GCMC simulation, where $D$ and $g$ denote the pore diameter of nanotubes and the separation

\begin{tabular}{|c|c|c|c|c|c|c|}
\hline \multirow{2}{*}{ SWNT } & \multirow{2}{*}{ Diameter/nm } & \multicolumn{2}{|c|}{ Unit cell } & \multirow{2}{*}{$\rho /\left(\mathrm{g} \cdot \mathrm{cm}^{-3}\right)$} & \multirow{2}{*}{$V /\left(\mathrm{cm}^{3} \cdot \mathrm{g}^{-1}\right)$} & \multirow{2}{*}{$\varphi$} \\
\hline & & $a / \mathrm{nm}$ & $b / \mathrm{nm}$ & & & \\
\hline$(8,8)$ & 1.085 & 1.485 & 2.572 & 1.36 & 0.33 & 0.45 \\
\hline$(10,10)$ & 1.356 & 1.756 & 3.041 & 1.21 & 0.42 & 0.51 \\
\hline$(12,12)$ & 1.627 & 2.027 & 3.511 & 1.09 & 0.51 & 0.55 \\
\hline$(15,15)$ & 2.034 & 2.424 & 4.198 & 0.96 & 0.64 & 0.61 \\
\hline$(18,18)$ & 2.441 & 2.841 & 4.921 & 0.84 & 0.79 & 0.66 \\
\hline$(20,20)$ & 2.710 & 3.112 & 5.390 & 0.77 & 0.88 & 0.68 \\
\hline \multicolumn{7}{|c|}{$\begin{array}{l}\rho \text { is the material's density, } V \text { is the pore volume, and } \varphi \text { is the porosity defined as } \\
\text { the ratio of the pore volume of adsorbent accessible to gas molecules to the } \\
\text { adsorbent volume. The pore volume is calculated by a Monte Carlo integration } \\
\text { with the reentrant surface definition, }{ }^{3} \text { where the argon molecule with a }\end{array}$} \\
\hline
\end{tabular}
between nanotubes, respectively.
Table 2 Structural properties for SWNT bundles

all of the adsorbed molecules; for $\mathrm{C}_{6} \mathrm{H}_{6}$ molecules $\beta$ is the angle between the normal vector to the benzene ring plane and the pore axis, and $S_{z} \approx-0.5,1$ denote that the molecules are parallel and perpendicular to the pore axis, respectively; for $\mathrm{N}_{2}$ and $\mathrm{O}_{2}$ molecules $\beta$ is the angle between the linear vector and the pore axis, and $S \approx-0.5,1$ denote that the molecules are perpendicular and parallel to the pore axis, respectively; for all the molecules $S_{z} \approx 0$ denotes that the molecules have no particular orientation.

\section{Results and discussion}

\subsection{Adsorption of pure benzene vapor on SWNTs}

Fig.2 shows the adsorption isotherms and isosteric heats of pure benzene in SWNTs at 303 K. From Fig.2(a, b), we can see that the capillary condensation occurs at high pressures for all the adsorption isotherms. In addition, the smaller the pore diameter, the lower the pressure at inflection point. Additionally, the saturation uptake increases with the nanotube diameter, which can be explained by the material structural data. As shown in Table 2, the pore volume increases with increasing the pore diameter, while the SWNT density decreases oppositely with increasing the pore size. Consequently, the SWNTs with large pore diameter can accommodate more benzene molecules, but with less material mass. It is clear that the $(20,20)$ SWNT is more suitable to adsorb pure benzene vapor. From Fig.2(b), we can also observe that the adsorption isotherms of $(15,15),(18,18)$, and $(20,20)$ SWNTs first slightly rise up before the sudden jumps of uptakes. This is because the interstices between these SWNTs can provide additional adsorption positions for benzene molecules. However, the prior ascending behavior is not found for $(8,8),(10,10)$, and $(12,12)$ SWNTs, since the interstices in these materials are inaccessible to the adsorbate molecules (see Fig.2(a)).

It is also found that the isotherm shapes in the nanotubes are similar to those in the slit pores. ${ }^{21}$ Moreover, the jumping pressure is strongly influenced by the pore diameter for changing several orders of magnitude, which is identical to the slit pores. ${ }^{21}$ Furthermore, in the MCM-41 material with the average pore diameter of $3.52 \mathrm{~nm},{ }^{22}$ the saturated adsorption amount of benzene is approximately equivalent in the pore size of $2.710 \mathrm{~nm}$ for $(20,20)$ nanotube, both approaching to $\sim 10 \mathrm{mmol} \cdot \mathrm{g}^{-1}$. Fig.2(c) shows the 

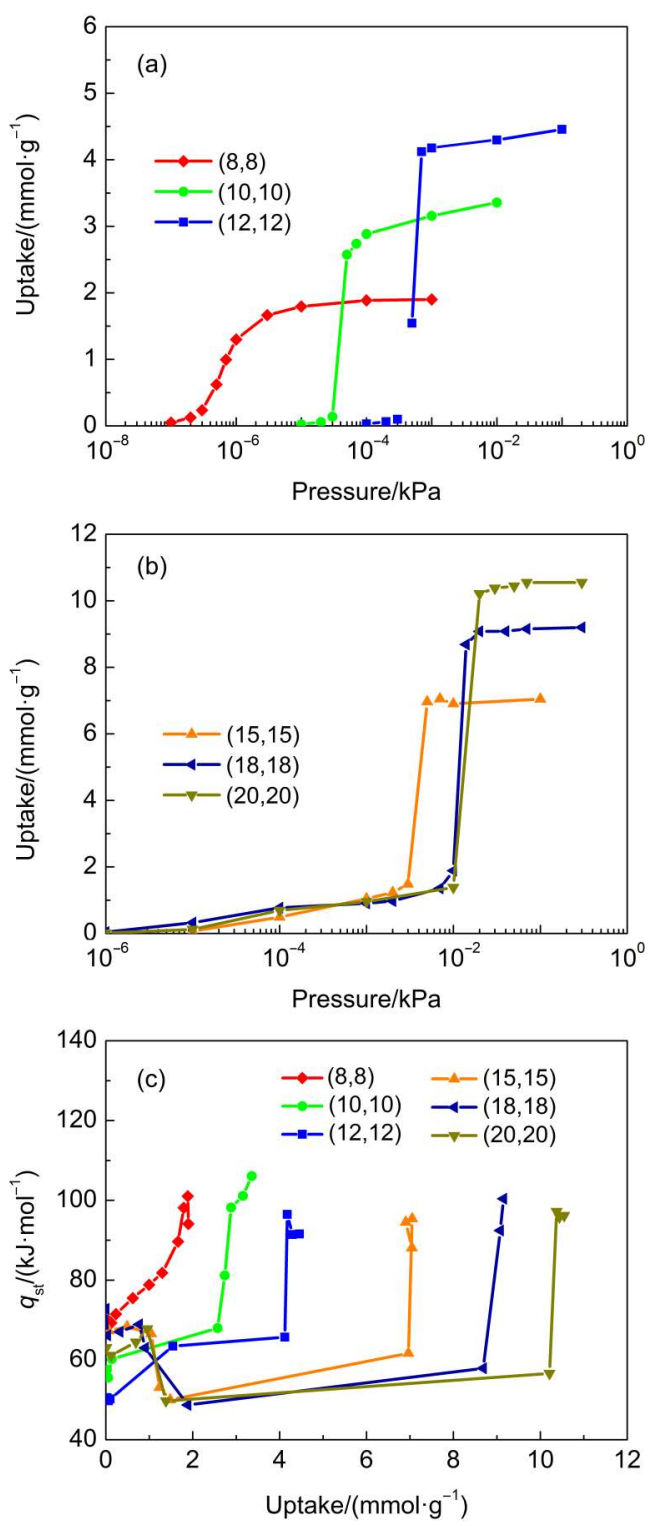

Fig.2 Adsorption isotherms and isosteric heats of pure benzene in SWNTs with different pore diameters at $303 \mathrm{~K}$

dependence of the isosteric heat on the uptake of benzene at different pore diameters. Before the adsorptions are saturated, narrowing pore size will increase the isosteric heat of adsorption, due to the greater contribution to the isosteric heats from the fluid-adsorbent interaction at smaller pores. At saturated uptakes, the fluid-fluid interaction plays a more important role in affecting the isosteric heats. Yang et al. ${ }^{23}$ reported the $\mathrm{N}_{2} / \mathrm{CO}_{2}$ adsorption in IRMOF-10. In their work, the isosteric heat curve exhibits a sudden jump before adsorption condensation. Furthermore, the isosteric heats contributed from $\mathrm{CO}_{2}-\mathrm{CO}_{2}$ interaction are much higher than those from $\mathrm{CO}_{2}-\mathrm{MOF}$ interaction. Clearly, their findings validate our results of the benzene adsorption in nanotube.

For the $(15,15),(18,18)$, and $(20,20)$ SWNTs, the isosteric heats exhibit a local maximum near $1 \mathrm{mmol} \cdot \mathrm{g}^{-1}$, then decline to the plateaus which correspond to the inflection point of pressure on the adsorption isotherms, and finally rise up sharply. By contrast, the isosteric heats present a continuous rising for $(8,8),(10,10)$, and $(12,12)$ SWNTs. This remarkable discrepancy can be attributed to the different adsorption positions between two types of SWNTs, which is also consistent with the discussion of their adsorption isotherms aforementioned. It is also observed that the isosteric heats in the nanotubes fluctuate in the range of 50-100 $\mathrm{kJ} \cdot \mathrm{mol}^{-1}$. Coasne et al. ${ }^{24}$ simulated the benzene adsorption in MCM-41 with a pore diameter of $3.6 \mathrm{~nm}$ at $298 \mathrm{~K}$. Their isosteric heats vary between 50 and $100 \mathrm{~kJ} \cdot \mathrm{mol}^{-1}$. This range is consistent with our case in nanotubes. In the works of Song ${ }^{25}$ and Zeng ${ }^{26}$ et al., the isosteric heats in silicalite- 1 and $\mathrm{NaY}$ zeolite fluctuate in 50-70 and 80-95 $\mathrm{kJ} \cdot \mathrm{mol}^{-1}$, respectively. All these comparisons indicate that the isosteric heats of benzene adsorption are greatly dependent on the types of porous materials.

\subsection{Separation of benzene from air by SWNTs}

Generally speaking, the exhaust gas with a benzene concentration of $50-1000 \mathrm{mg} \cdot \mathrm{m}^{-3}$ belongs to the waste gas containing a low concentration of benzene. In this work, we specify $300 \times 10^{-6}$ as the typical concentration of benzene in air. Therefore, the mole composition of $\mathrm{C}_{6} \mathrm{H}_{6} / \mathrm{N}_{2} / \mathrm{O}_{2}$ gas system is 0.0003:0.79:0.2097. The simulated total pressure is no more than $4.0 \mathrm{MPa}$ to ensure that the benzene in the bulk phase is still in the gas state, because the partial pressure of benzene is $1.2 \mathrm{kPa}$ at this gas composition, which is much smaller than the saturated vapor pressure of 15.9 $\mathrm{kPa}$. Figs.S1-S6 (Supporting Information) show the pairwise adsorption selectivities of $\mathrm{C}_{6} \mathrm{H}_{6} / \mathrm{O}_{2}, \mathrm{C}_{6} \mathrm{H}_{6} / \mathrm{N}_{2}, \mathrm{~N}_{2} / \mathrm{O}_{2}$ and the single component isotherms at different pore diameters. As expected, the selectivities of $\mathrm{C}_{6} \mathrm{H}_{6} / \mathrm{O}_{2}$ and $\mathrm{C}_{6} \mathrm{H}_{6} / \mathrm{N}_{2}$ are several orders of magnitude higher than that of $\mathrm{N}_{2} / \mathrm{O}_{2}$, indicating that $\mathrm{C}_{6} \mathrm{H}_{6}$ is the most preferentially adsorbed among these species. Fig. 3 shows the effects of the pressure and pore size on the selectivity of $\mathrm{C}_{6} \mathrm{H}_{6} /\left(\mathrm{N}_{2}+\right.$ $\mathrm{O}_{2}$ ). As we can see, for all the SWNTs, $\mathrm{C}_{6} \mathrm{H}_{6}$ reaches saturation adsorption at relatively low pressures, while the adsorption isotherms of $\mathrm{N}_{2}$ and $\mathrm{O}_{2}$ increase all along with the pressure. Accordingly, the selectivity of $\mathrm{C}_{6} \mathrm{H}_{6}$ gradually decreases with the pressure. Another factor that distinctly affects the adsorption selectivity is the pore diameter. Interestingly, we see that for all the pressures, the selectivities exhibit a minimum at the pore diameters $D=1.5 \mathrm{~nm}$ for $(12,12) \mathrm{SWNT}$, and a maximum at $D=2.5 \mathrm{~nm}$ for $(18,18)$ SWNT, respectively, which is caused by the different responses of the component uptake to the pore diameter. As seen in Fig.3, the benzene adsorption in air can be enhanced by the pore diameter monotonously. Nevertheless, with the increase of the pore size, the uptakes of $\mathrm{N}_{2}$ and $\mathrm{O}_{2}$ transfer from the maximum to the minimum. Consequently, the $(18,18)$ SWNT is the optimal material for purifying trace benzene, because both selectivity and capacity are significantly improved.

\subsection{Microscopic structure of benzene mixture adsorption in SWNTs}

To further understand the extremes of adsorption isotherms in Fig.3, we analyze the adsorption structures for $(12,12)$ and $(18,18)$ SWNTs. Fig. 4 shows the local density profiles of mass center and probability profiles of the ternary mixture. We can see that for $(12$, 

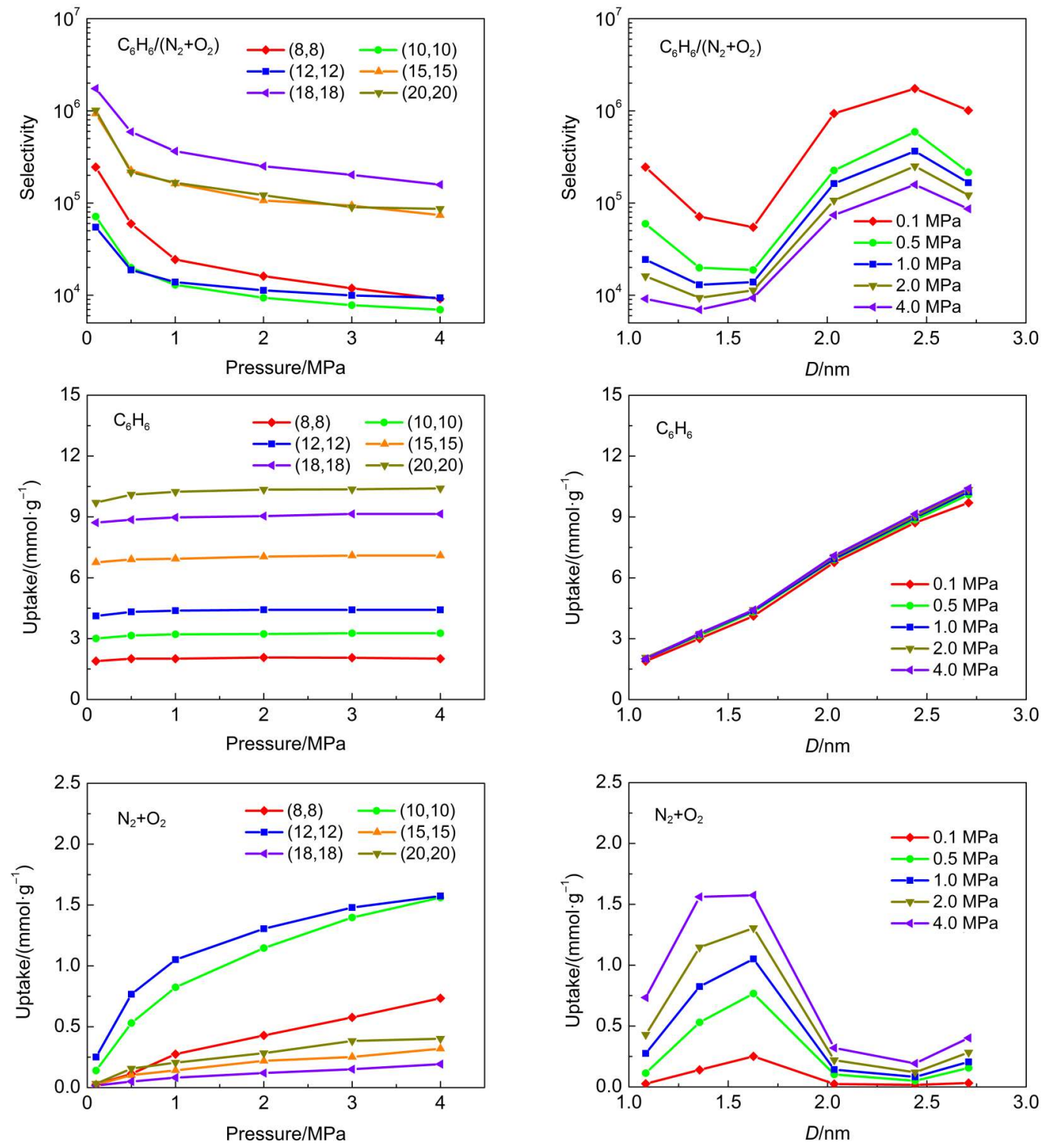

Fig.3 Effects of pressure and pore diameter of SWNTs on the adsorption of $\mathrm{N}_{2}-\mathrm{O}_{2}-\mathrm{C}_{6} \mathrm{H}_{6}$ ternary mixtures at $303 \mathrm{~K}$

12) SWNT at 4.0 MPa, the local density profiles of $\mathrm{N}_{2}$ and $\mathrm{O}_{2}$ exhibit three sharp peaks at $r=0.6,1.5,2.1 \mathrm{~nm}$, corresponding to the adsorptions in the interstices of SWNTs. Although the interstices is narrow, it can provide efficient adsorption positions for these small molecules, where the fluid-solid interaction potentials between the nanotubes overlap each other. However, the adsorption of $\mathrm{C}_{6} \mathrm{H}_{6}$ in $(12,12)$ SWNT mainly occurs inside the tubes, which is validated by the probability profiles. For $(18,18)$ SWNT at $0.1 \mathrm{MPa}$, no peaks are observed for the adsorptions of $\mathrm{N}_{2}$ and $\mathrm{O}_{2}$. By contrast, the local density profile of $\mathrm{C}_{6} \mathrm{H}_{6}$ exhibits distinct peaks at $r=0.3,0.8,1.6,2.1 \mathrm{~nm}$, in succession with the adsorptions that occur in the center of tube, on the inner surface of tube, and as the nearest and the second nearest layers in interstices. It indicates that the adsorption of $\mathrm{C}_{6} \mathrm{H}_{6}$ is favored at low pressures and large pores where the adsorption separation ability is dominated by the enthalpy effect and the entropy effect, respectively. However, a small quantity of $\mathrm{N}_{2}$ and $\mathrm{O}_{2}$ molecules emerge only in the interstices at a high pressure of 4.0 $\mathrm{MPa}$. The discussion is also consistent with the adsorption snapshots in Fig.5.

In order to characterize the orientations of adsorbed molecules with respect to the pore axis of the SWNTs, we calculated the order parameter $S_{z}(r)$ as a function of the distance $r$ from the center of simulation box to the mass center of adsorbate. From Fig.6, we can see that for both materials the benzene molecules in the contact layer and interstices give an approximate value of -0.5 for $S_{z}$, which shows that these benzene molecules prefer an orientation lying nearly flat on the pore surface. Interestingly, for (18, 18) SWNT, the benzene molecules beyond the contact layer ( $r=$ $0.7 \mathrm{~nm}$ ) show a different orientation, where their benzene rings are nearly perpendicular to the pore axis. This is because these molecules tend to recover their bulk properties for the less confinement. Note that the above orientation profiles are also in good consistence with the molecular dynamic simulations by Bhide and Yashonath. ${ }^{27}$ For $\mathrm{N}_{2}$ and $\mathrm{O}_{2}$ molecules, their orientations in both 

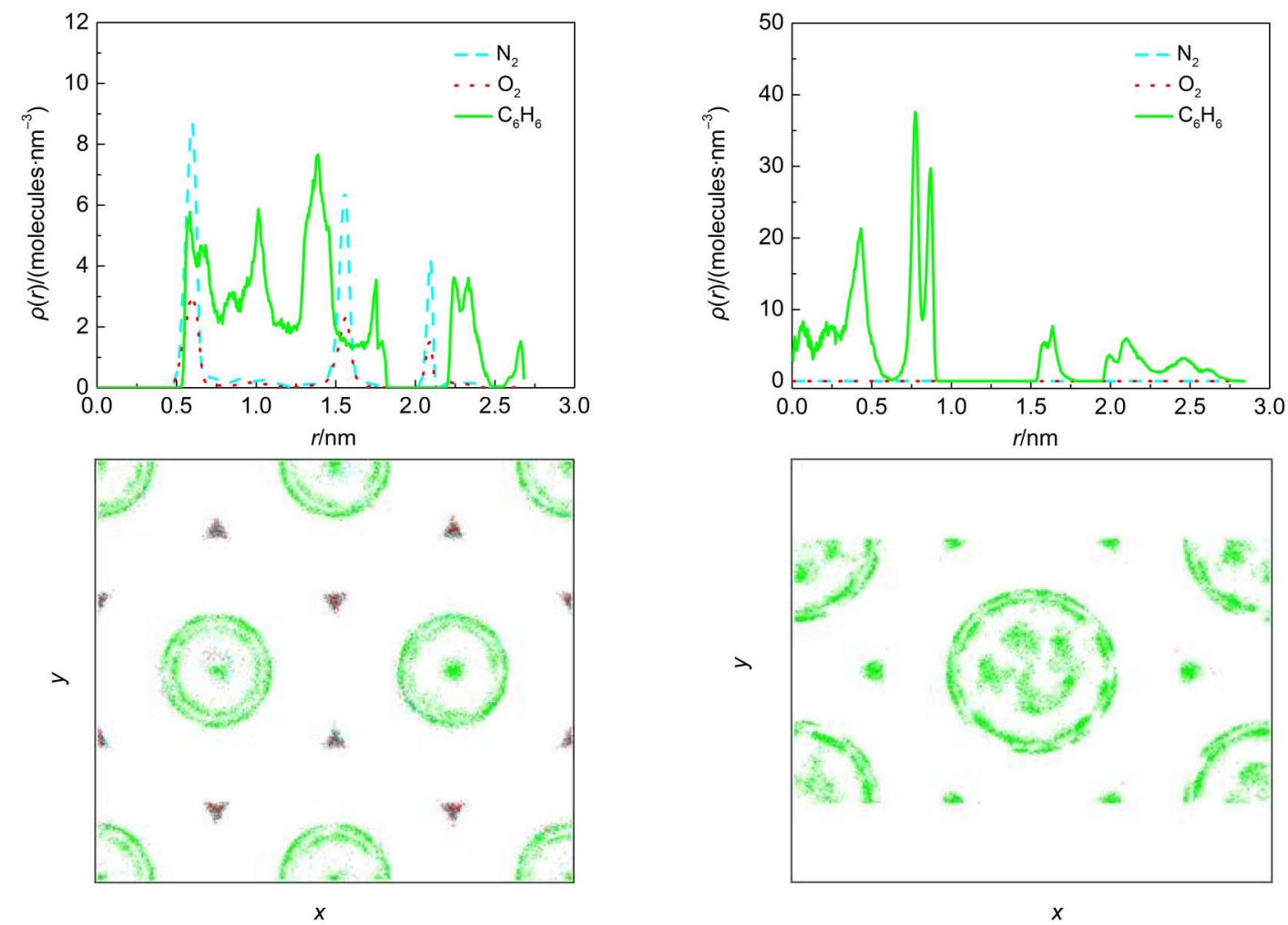

Fig.4 Local density profiles (top panels) of molecular mass center as a function of the distance $r$, and probability profiles (bottom panels) of molecular mass center from top views for $\mathrm{N}_{2}-\mathrm{O}_{2}-\mathrm{C}_{6} \mathrm{H}_{6}$ adsorption

The left panels are for SWNTs $(12,12)$ at $4.0 \mathrm{MPa}$ and the right panels are for SWNTs $(18,18)$ at $0.1 \mathrm{MPa}$. The coordination origin is in the center of simulation box.
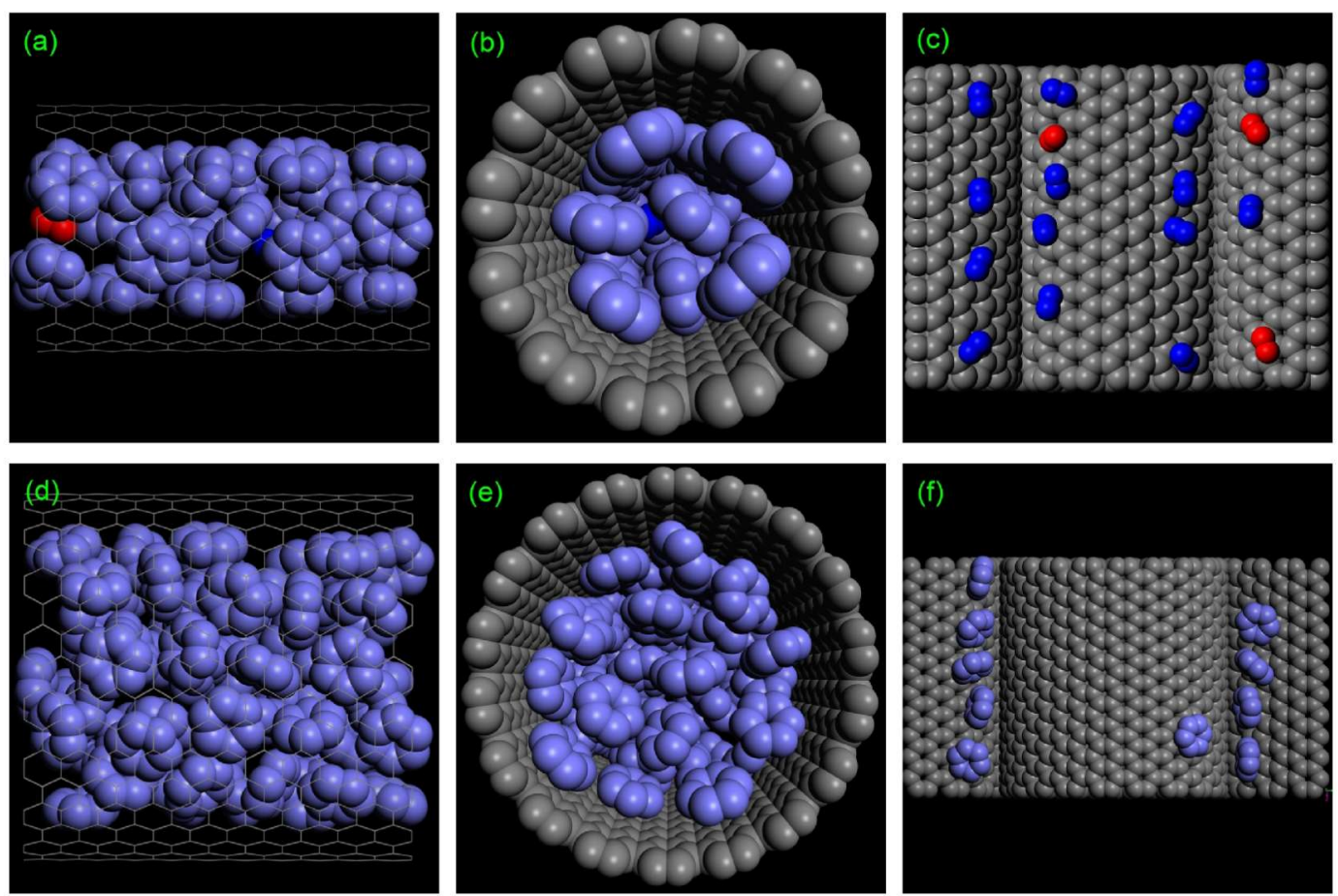

Fig.5 Snapshots of $\mathrm{N}_{2}-\mathrm{O}_{2}-\mathrm{C}_{6} \mathrm{H}_{6}$ ternary mixtures in SWNTs

(a-c) SWNTs $(12,12)$ at $4.0 \mathrm{MPa},(\mathrm{d}-\mathrm{f})$ SWNTs $(18,18)$ at $0.1 \mathrm{MPa}$. (c) and (f) are adsorptions in the interstices between tubes, others are inside tubes.

materials are basically identical, i.e., adopting a parallel angle to the pore axis. All these preferential orientations also can be seen in the molecular configurations in Fig.5.

\subsection{Effects of temperature and concentration on benzene separation}

Fig.7 shows the effect of temperature on the separation of 

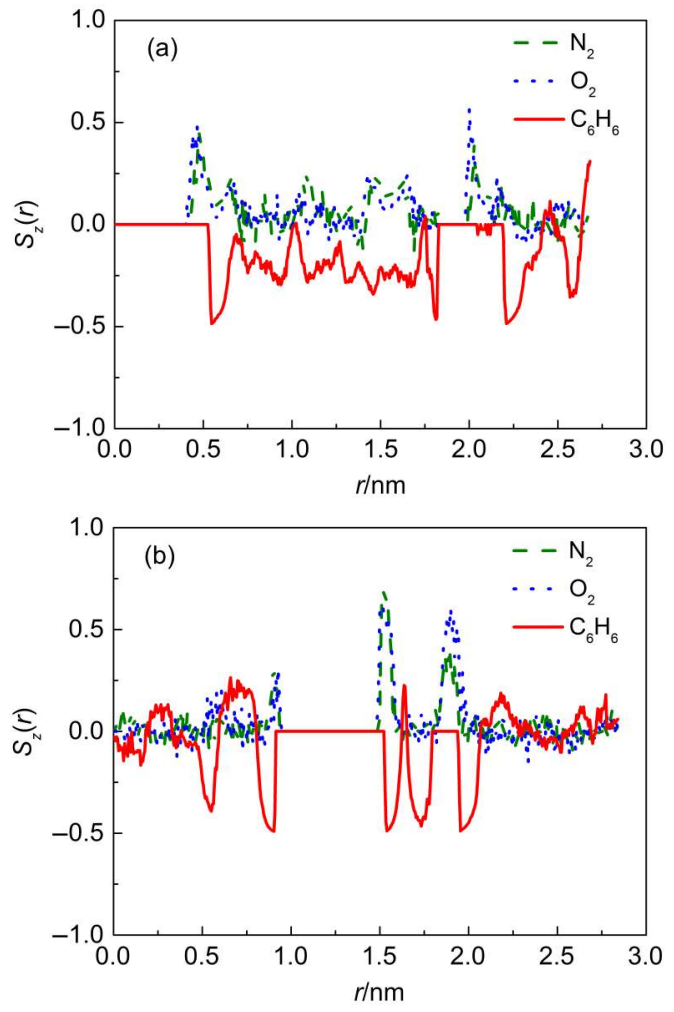

Fig.6 Orientational order parameters $S_{z}(r)$ of adsorbed $\mathrm{N}_{2}-\mathrm{O}_{2}-$ $\mathrm{C}_{6} \mathrm{H}_{6}$ ternary mixtures

(a) SWNTs $(12,12)$ at $4.0 \mathrm{MPa}$, (b) SWNTs $(18,18)$ at $0.1 \mathrm{MPa}$

benzene at the SWNTs with different pore sizes. It is well known that the increase of temperature will reduce the adsorption se-
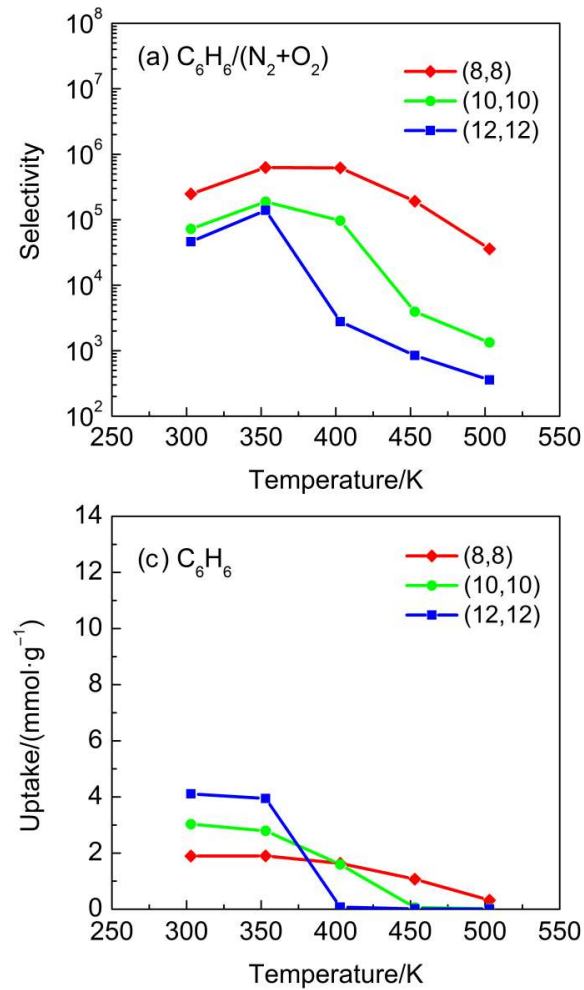

lectivity, which is confirmed by the adsorption behaviors in (15, 15), (18,18), and $(20,20)$ SWNTs. Furthermore, Fig.7(d) shows that the uptakes of benzene fall down sharply from the saturated amount to $1 \mathrm{mmol} \cdot \mathrm{g}^{-1}$ when the temperature is increased by $50 \mathrm{~K}$. However, a further release of benzene is quite difficult, since it requires a large temperature rise of $150 \mathrm{~K}$ to completely remove the residue. Accordingly, the selectivity curve declines in the whole temperature range, as shown in Fig.7(b). However, for $(8$, $8),(10,10)$, and $(12,12)$ SWNTs, the situation is a little different from the previous case. From Fig.7(a), we see that with the increase of temperature, the selectivity of benzene shows a rise first, and then drops down. However, the uptakes of benzene are almost constant in the initial heating process (see Fig.7(c)). Consequently, this prior ascending of selectivity can only be interpreted by the sharper decrease of the uptakes of $\mathrm{N}_{2}$ and $\mathrm{O}_{2}$ molecules. By comparing these two types of SWNTs, we found that the selectivities and uptakes in the larger pores where the confinement effect is weaker, are more influenced by the temperature. Clearly, from the viewpoint of adsorbent regeneration, the temperature swing adsorption (TSA) process could be an appropriate way for the best carbon nanotube material of $(18,18)$ SWNTs for benzene purification.

Fig. 8 shows the dependence of the selectivity and uptake on the benzene concentration of bulk phase. From Fig.8(d), we can see that the uptakes of benzene go up drastically in the large pores. However, the selectivities of benzene exhibit a slight decrease because the concentration of benzene in the bulk phase increases greater than that in the pore phase by several orders of magnitude
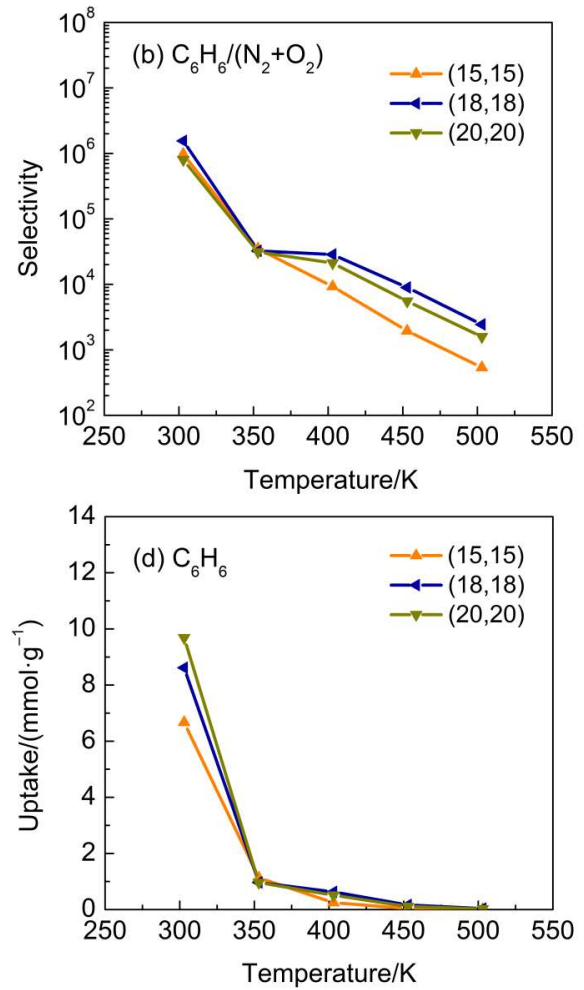

Fig.7 Effect of temperature on the adsorption of $\mathrm{N}_{2}-\mathrm{O}_{2}-\mathrm{C}_{6} \mathrm{H}_{6}$ ternary mixtures in SWNTs at 0.1 MPa 

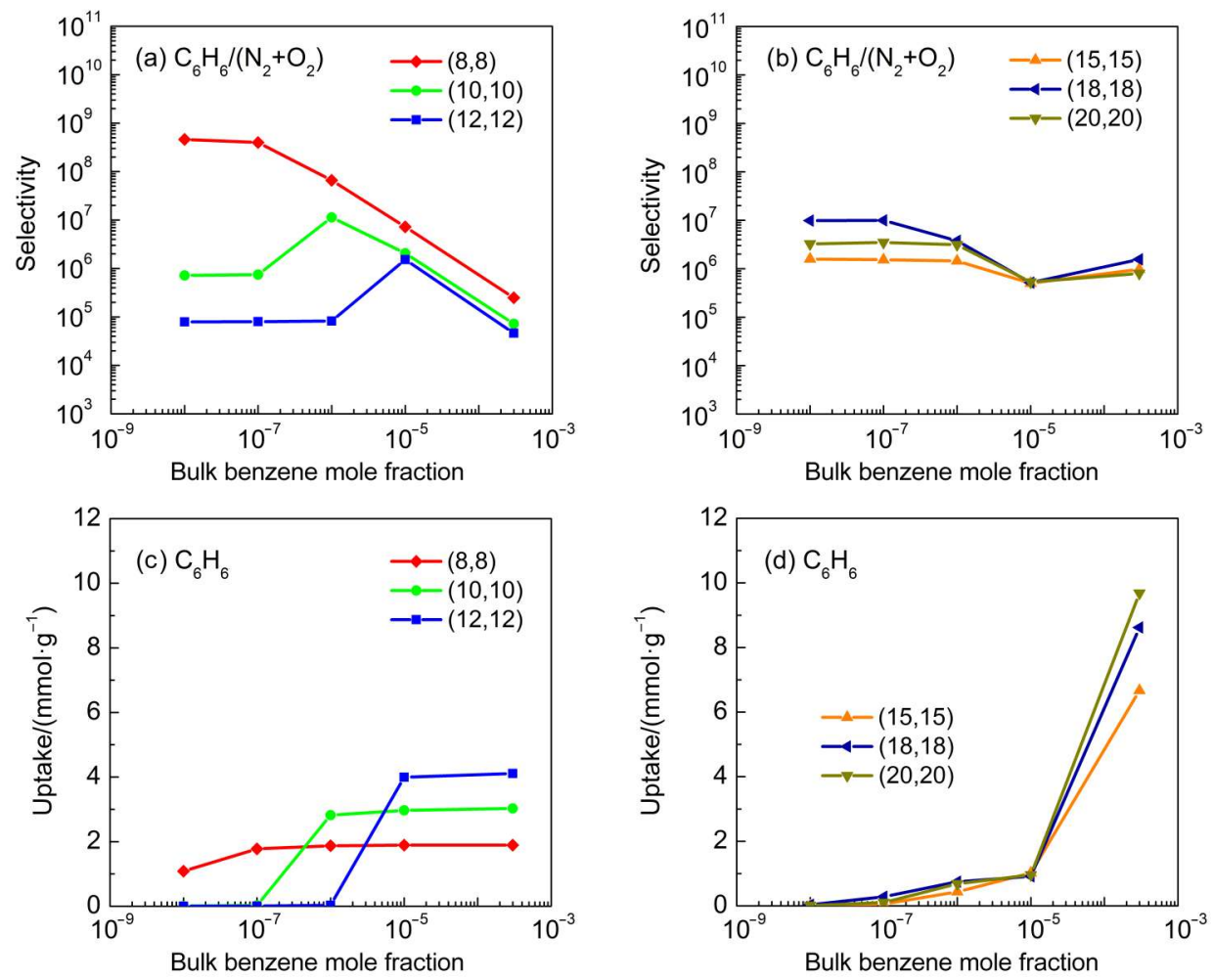

Fig.8 Effect of bulk benzene concentrations on the adsorption of $\mathrm{N}_{2}-\mathrm{O}_{2}-\mathrm{C}_{6} \mathrm{H}_{6}$ ternary mixtures in SWNTs at $303 \mathrm{~K}$ and $0.1 \mathrm{MPa}$

(see Fig.8(b)). The similar behavior can be observed in the small pores. However, for the $(10,10)$ and $(12,12)$ SWNTs, the uptakes undergo an increase first and then reach a stable plateau (see Fig. 8 (c)). As a result, there appears a maximum of the benzene selectivity in Fig.8(a).

\section{Conclusions}

By using grand canonical Monte Carlo simulation technique, we have systematically investigated the purification of benzene from air in SWNTs. We find that a large pore size of $(20,20)$ SWNT is more efficient to adsorb pure benzene vapor. However, for the removal of trace benzene in air, $(18,18)$ SWNT is the best separation material, because the maximum of selectivity $\left(>10^{6}\right)$ is obtained at $0.1 \mathrm{MPa}$. The microscopic structures such as molecular configurations, local density profiles, and probability profiles are further analyzed for the $\mathrm{N}_{2}-\mathrm{O}_{2}-\mathrm{C}_{6} \mathrm{H}_{6}$ mixture. We observe that $(18,18)$ SWNT only adsorbs the benzene molecules. The orientation order parameters indicate that benzene molecules nearly flat on the pore surface. The effects of temperature and concentration of bulk benzene on the selectivity of benzene are finally studied. Our simulations reveal that the carbon nanotubes could be excellent adsorbents in effectively purifying the toxic benzene impurity in air.

Supporting Information: The adsorption selectivities and single-component isotherms of ternary mixtures in six SWNT bundles have been included. This information is available free of charge via the internet at http://www.whxb.pku.edu.cn.

\section{References}

(1) Benzene Poisoning in Chemical Laboratories. J. Chem. Educ. 1929, 6, 513.

(2) Yan, Y. P.; Chen, F. Z.; Shao, Y. X. Tech. Equip. Environmental Pollut. Control 2000, 1, 76. [颜幼平, 陈凡植, 邵英贤. 环境污 染治理技术与设备, 2000, 1, 76.]

(3) Peng, X.; Cao, D. AIChE J. 2013, 59, 2928. doi: 10.1002/aic. v59.8

(4) Peng, X.; Cheng, X.; Cao, D. J. Mater. Chem. 2011, 21, 11259. doi: $10.1039 / \mathrm{c} 1 \mathrm{jm} 10264 \mathrm{~h}$

(5) Do, D. D.; Do, H. D. Langmuir 2006, 22, 1121. doi: 10.1021/ $1 \mathrm{a} 052545 \mathrm{i}$

(6) Coasne, B.; Fourkas, J. T.; Normale, E. J. Phys. Chem. C 2011, 115, 15471. doi: 10.1021/jp203831q

(7) Jousse, F.; Auerbach, S. M.; Vercauteren, D. P. J. Phys. Chem. B 2000, 104, 2360. doi: 10.1021/jp9935642

(8) Amirjalayer, S.; Tafipolsky, M.; Schmid, R. Angew. Chem. Int. Edit. 2007, 46, 463.

(9) Iijima, S. Nature 1991, 354, 56. doi: 10.1038/354056a0

(10) Cinke, M.; Li, J.; Bauschlicher, C. W.; Ricca, A.; Meyyappan, M. Chem. Phys. Lett. 2003, 376, 761. doi: 10.1016/S0009-2614 (03)01124-2

(11) Wang, W.; Peng, X.; Cao, D. Environ. Sci. Technol. 2011, 45, 4832. doi: 10.1021/es 1043672

(12) Huang, L.; Zhang, L.; Shao, Q.; Lu, L.; Lu, X.; Jiang, S.; Shen, W. J. Phys. Chem. C 2007, 111, 11912. doi: 10.1021/jp067226u

(13) Bonnaud, P.; Nieto-Draghi, C.; Ungerer, P. J. Phys. Chem. B 
2007, 111, 3730. doi: 10.1021/jp067695w

(14) Perng, B.; Sasaki, S.; Ladanyi, B. M.; Everitt, K. F.; Skinner, J.

L. Chem. Phys. Lett. 2001, 348, 491. doi: 10.1016/S0009-2614 (01)01152-6

(15) Potoff, J. J.; Siepmann, J. I. AIChE J. 2001, 47, 1676.

(16) Frenkel, D.; Berend, S. Understanding Molecular Simulation; Academic Press: London, 2002.

(17) Kowalczyk, P.; Holyst, R. Environ. Sci. Technol. 2008, 42, 2931. doi: 10.1021/es071306+

(18) Wolf, D.; Keblinski, P.; Phillpot, S. R.; Eggebrecht, J. J. Chem. Phys. 1999, 110, 8254. doi: 10.1063/1.478738

(19) Peng, X.; Cao, D.; Wang, W. Ind. Eng. Chem. Res. 2010, 49, 8787. doi: 10.1021/ie1010433

(20) Peng, X.; Wang, W.; Xue, R.; Shen, Z. AIChE J. 2006, 52, 994.

(21) Coasne, B.; Alba-Simionesco, C.; Audonnet, F.; Dosseh, G.;
Gubbins, K. Phys. Chem. Chem. Phys. 2011, 13, 3748. doi: $10.1039 / \mathrm{c} 0 \mathrm{cp} 02205 \mathrm{e}$

(22) Nguyen, D.; Do, D. J. Phys. Chem. B 2000, 104, 11435. doi: 10.1021/jp0007282

(23) Yang, Q.; Ma, L.; Zhong, C.; An, X.; Liu, D. J. Phys. Chem. C 2011, 115, 2790. doi: 10.1021/jp1101835

(24) Coasne, B.; Alba-Simionesco, C.; Audonnet, F.; Dosseh, G.; Gubbins, K. Adsorption 2007, 13, 485. doi: 10.1007/s10450007-9051-3

(25) Song, L.; Sun, Z.; Ban, H.; Dai, M.; Rees, L. Adsorption 2005, $11,325$.

(26) Zeng, Y.; Ju, S.; Xing, W.; Chen, C. Ind. Eng. Chem. Res. 2007, 46, 242. doi: 10.1021/ie060118+

(27) Bhide, S.; Yashonath. S. J. Phys. Chem. B 2000, 104, 11977. doi: 10.1021/jp002626h 
Supplementary Information for Acta Phys. -Chim. Sin. 2014, 30 (11), 2000-2008 doi: 10.3866/PKU.WHXB201408291

\title{
单壁碳纳米管上毒性苯气体净化的分子模拟
}

\author{
彭 璇* \\ (北京化工大学信息科学与技术学院，北京 100029)
}

\section{Molecular Simulations of the Purification of Toxic Benzene Gas on Single-Walled Carbon Nanotubes}

\author{
PENG Xuan* \\ (College of Information Science and Technology, Beijing University of Chemical Technology, Beijing 100029, P. \\ R. China)
}



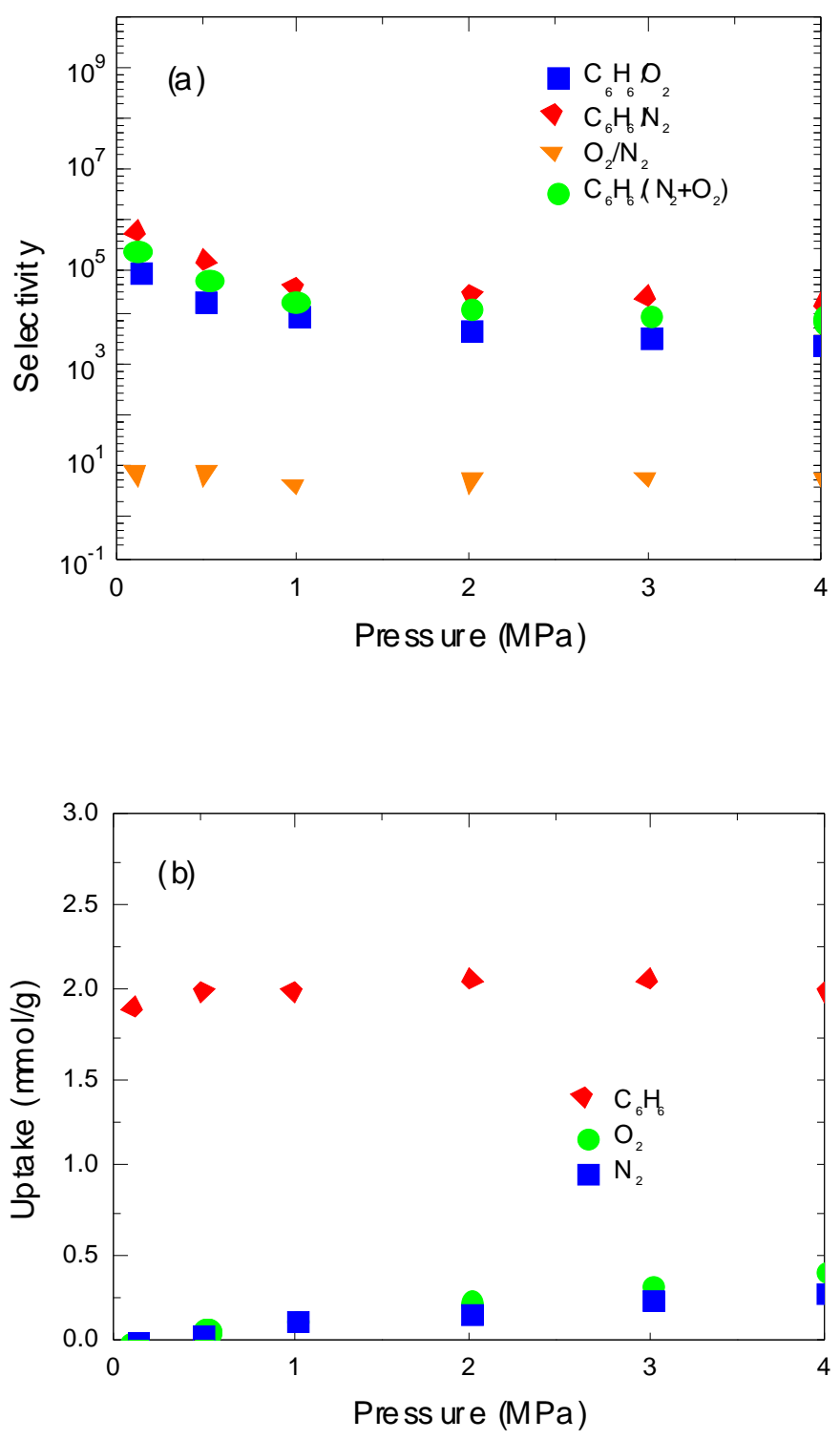

Fig.S1 Adsorption selectivities and isotherms of $\mathrm{N}_{2}-\mathrm{O}_{2}-\mathrm{C}_{6} \mathrm{H}_{6}$ ternary mixtures $\left(y_{\mathrm{N} 2}=0.79\right.$ and $\left.y_{\mathrm{C} 6 \mathrm{H} 6}=0.0003\right)$ in $(08,08)$ SWNTs at $303 \mathrm{~K}$ 

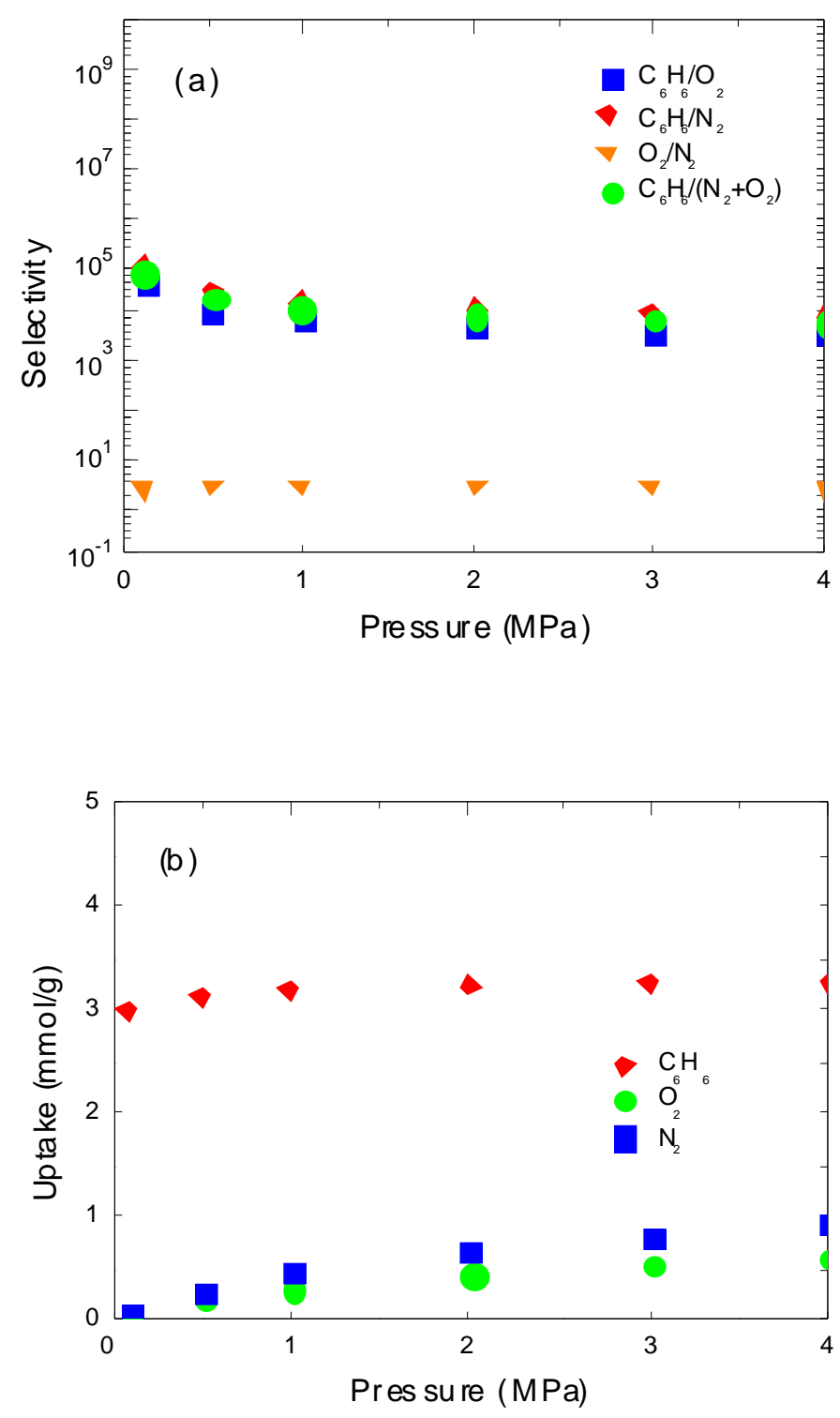

Fig.S2 Adsorption selectivities and isotherms of $\mathrm{N}_{2}-\mathrm{O}_{2}-\mathrm{C}_{6} \mathrm{H}_{6}$ ternary mixtures $\left(y_{\mathrm{N} 2}=0.79\right.$ and $\left.y_{\mathrm{C} 6 \mathrm{H} 6}=0.0003\right)$ in $(10,10)$ SWNTs at $303 \mathrm{~K}$ 

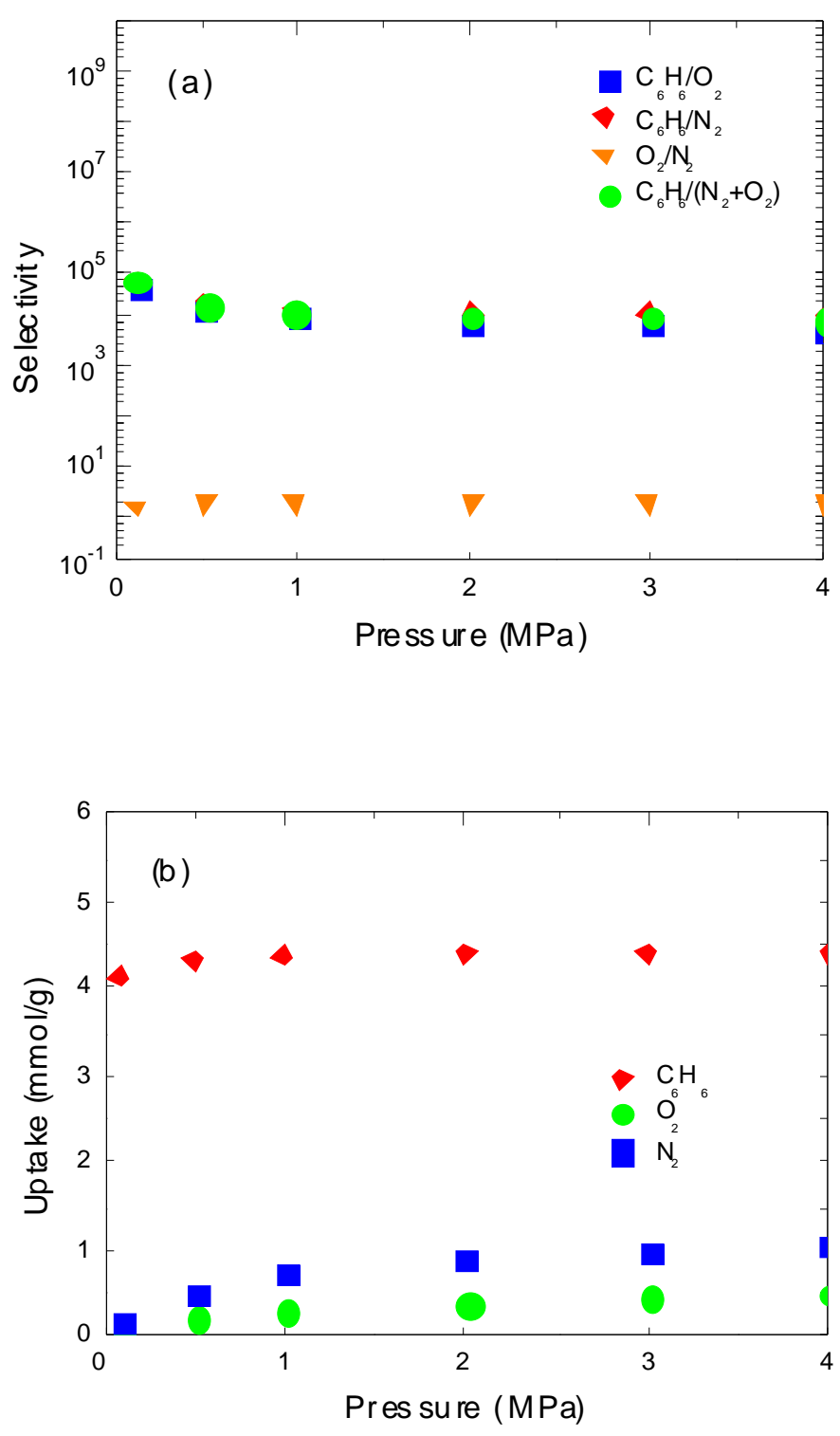

Fig.S3 Adsorption selectivities and isotherms of $\mathrm{N}_{2}-\mathrm{O}_{2}-\mathrm{C}_{6} \mathrm{H}_{6}$ ternary mixtures $\left(y_{\mathrm{N} 2}=0.79\right.$ and $\left.y_{\mathrm{C} 6 \mathrm{H} 6}=0.0003\right)$ in $(12,12)$ SWNTs at $303 \mathrm{~K}$ 

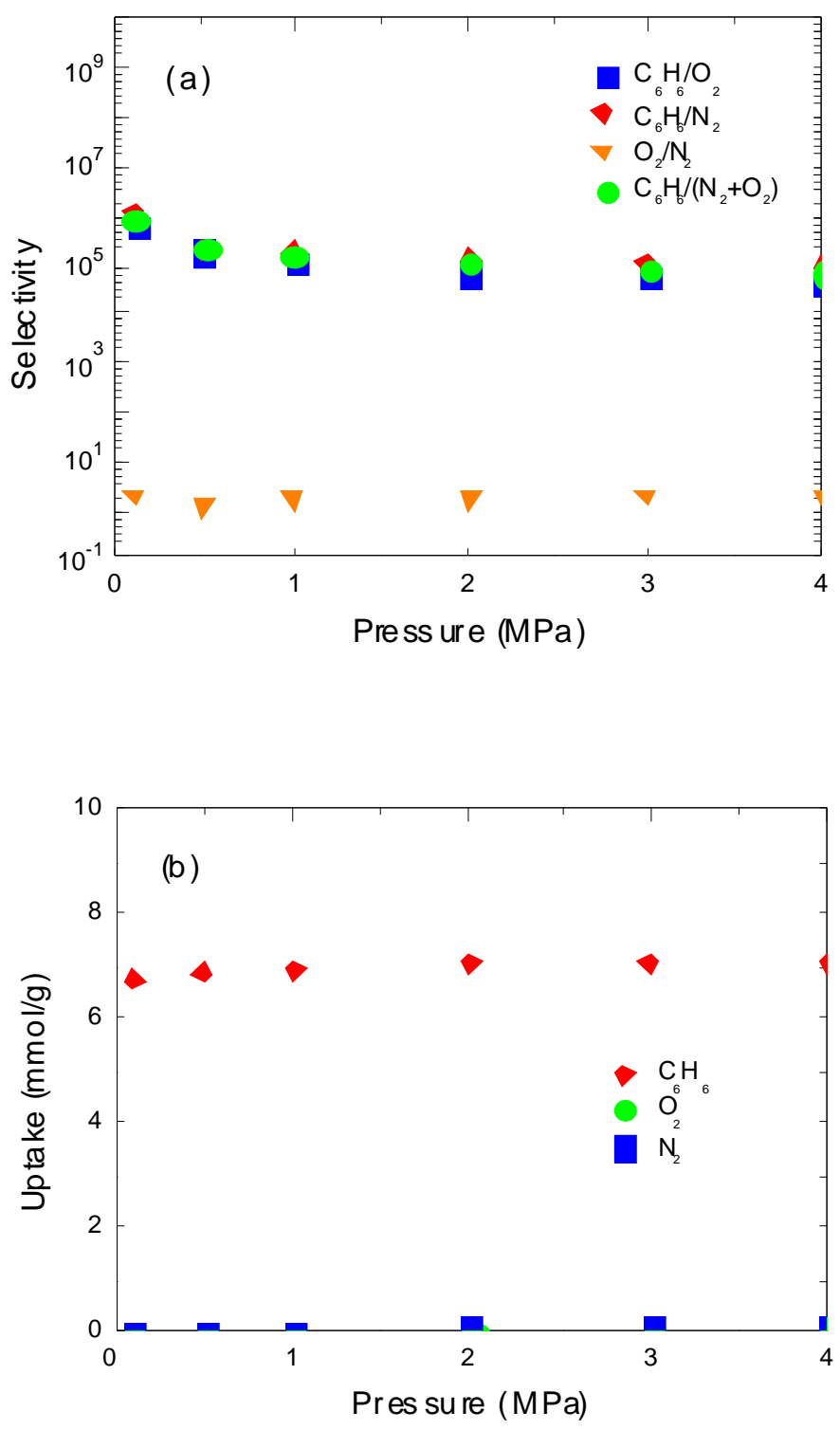

Fig.S4 Adsorption selectivities and isotherms of $\mathrm{N}_{2}-\mathrm{O}_{2}-\mathrm{C}_{6} \mathrm{H}_{6}$ ternary mixtures $\left(y_{\mathrm{N} 2}=0.79\right.$ and $\left.y_{\mathrm{C} 6 \mathrm{H} 6}=0.0003\right)$ in $(15,15)$ SWNTs at $303 \mathrm{~K}$ 

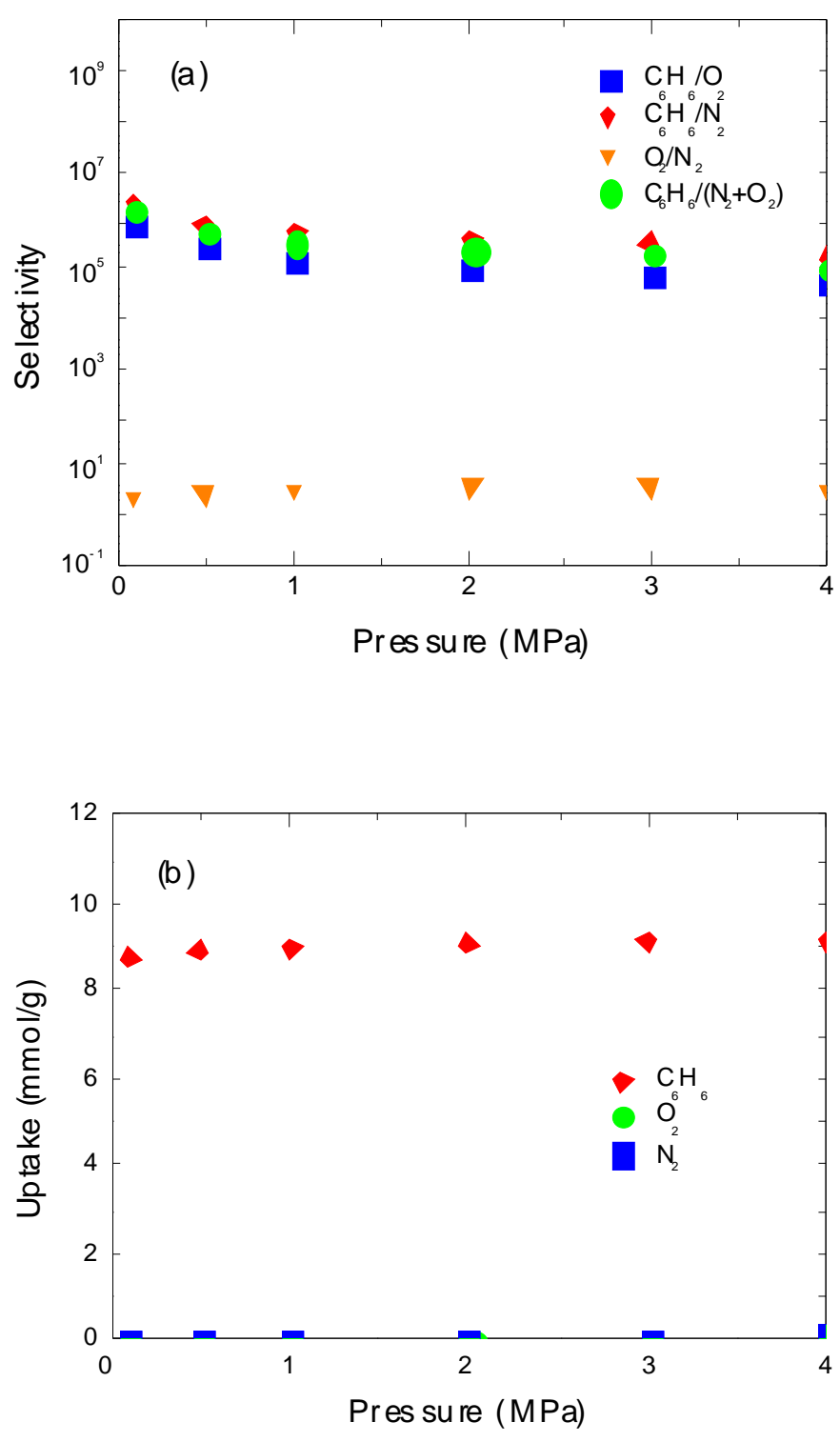

Fig.S5 Adsorption selectivities and isotherms of $\mathrm{N}_{2}-\mathrm{O}_{2}-\mathrm{C}_{6} \mathrm{H}_{6}$ ternary mixtures $\left(y_{\mathrm{N} 2}=0.79\right.$ and $\left.y_{\mathrm{C} 6 \mathrm{H} 6}=0.0003\right)$ in $(18,18)$ SWNTs at $303 \mathrm{~K}$ 

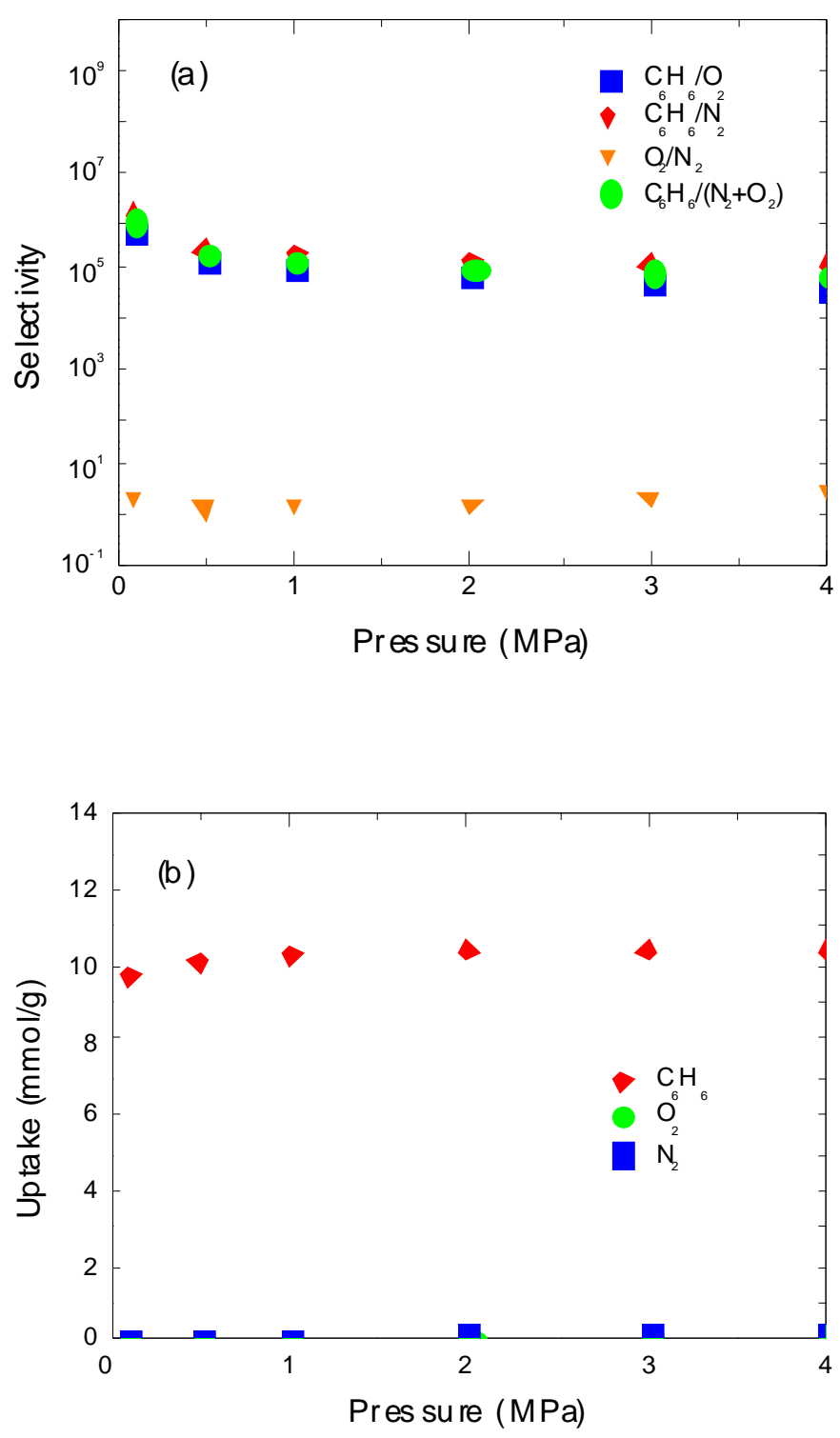

Fig.S6 Adsorption selectivities and isotherms of $\mathrm{N}_{2}-\mathrm{O}_{2}-\mathrm{C}_{6} \mathrm{H}_{6}$ ternary mixtures $\left(y_{\mathrm{N} 2}=0.79\right.$ and $\left.y_{\mathrm{C} 6 \mathrm{H} 6}=0.0003\right)$ in $(20,20)$ SWNTs at $303 \mathrm{~K}$ 